\title{
Trapping of plastics in semi-enclosed seas: Insights from the Bohai Sea, China
}

\author{
Yanfang $\mathrm{Li}^{\mathrm{a}}{ }^{\mathrm{a}}$, Eric Wolanski ${ }^{\mathrm{b}}$, Zhenfei Dai ${ }^{\mathrm{a}}$, Jonathan Lambrechts ${ }^{\mathrm{c}}$, Cheng Tang ${ }^{\mathrm{a}}$, Hua Zhang ${ }^{\mathrm{a}}$ \\ ${ }^{\text {a }}$ Key Laboratory of Coastal Zone Environmental Processes and Ecological Remediation, Yantai Institute of Coastal Zone Research, Chinese Academy of Sciences, Shandong, \\ China \\ ${ }^{\mathrm{b}}$ TropWATER and College of Science and Engineering, James Cook University, Townsville, Qld 4810, Australia \\ ${ }^{\mathrm{c}}$ Catholic University of Louvain, Institute of Mechanics, Materials and Civil Engineering (IMMC), B-1348 Louvain-la-Neuve, Belgium
}

A R T I C L E IN F O

\section{Keywords:}

Microplastics

Degradation

Settling

Wind effect

Currents

Source input

\begin{abstract}
A B S T R A C T
Microplastics are abundant in semi-enclosed seas, presumably because of local trapping. To investigate this trapping effect, we confronted the SLIM plastic oceanography model with field data of the distribution of microplastics in the Bohai Sea, China. Seven source locations were selected to reveal the fate of plastic debris from industrial and domestic usages. The model predictions compared well with the observed distribution of microplastics, highlighting that most plastics were trapped in the Bohai Sea. The model suggests that microplastics distribution within the Bohai Sea both in the water and on the bottom varies seasonally with wind and currents and depends on a complex interaction between source locations, prevailing hydrodynamic conditions, degradation, settling and resuspension rates. Further field studies are warranted to enable the models to better parameterize the fate of microplastics, and particularly the accumulation zones, in other poorly flushed semienclosed seas worldwide, where microplastics should be classified as a persistent pollutant.
\end{abstract}

\section{Introduction}

The worldwide production of plastic reached $2.5 \times 10^{8}$ metric tons in year 2015 (Jambeck et al., 2015) and at least $2.5 \times 10^{5}$ metric tons of plastics are currently floating in the oceans (Eriksen et al., 2014). Marine plastic pollution has become a global environmental problem; especially the most abundant and potentially toxic microplastics with particle sizes $<5 \mathrm{~mm}$ whose residence time in the marine environment has been estimated to be in the range of decades to centuries (Ballent et al., 2013) and this may imply long-term environmental risks to marine ecosystem. The ubiquitous presence of microplastics has been reported worldwide in various marine habitats, e.g., water column (Cozar et al., 2014), beach and wetland sediments (Browne et al., 2011; Hidalgo-Ruz et al., 2012), and even far from pollution sources (e.g. Welden and Lusher, 2017) including polar regions (Lusher et al., 2015) and deep seas (Van Cauwenberghe et al., 2013). Besides being a major driver of the water circulation (Hogan and Hurlburt, 2005), the wind also has a direct effect on the dispersal of floating macroplastics through the wind drift (Breivik et al., 2011; Lebreton and Borrero, 2013). Large amounts of trash can also be swept into the ocean by natural disasters such as tropical storms, the most significant case was in March 2011, a tsunami in Japan washed large amount of floating debris out into the North Pacific Ocean (Lebreton and Borrero, 2013). Coastal seas are hot spots of microplastic contamination due to the intensive human activities along shorelines (Cole et al., 2011; Zhang, 2017). High concentrations of microplastic are commonly observed in areas with high population density, near industrial sites or harbors (e.g. Claessens et al., 2011; Desforges et al., 2014; Auta et al., 2017). Plastic debris released into marine environment go through various transport pathways including degradation from macroplastics to microplastics, floating at the surface, vertical mixing in the water column, beaching and settling into sediment and occasional resuspension, and drifting at sea, as well as biological interactions (e.g. biofouling; Fazey and Ryan, 2016; Zhang, 2017) and incorporation in sediment flocs in suspension (Möhlenkamp et al., 2018). Both the density of sediment flocs, of the polymer and biofouling determine the buoyancy (Lobelle and Cunliffe, 2011), which in turn determines whether the plastic particles in the long-term eventually sink to the bottom or float on the surface to ultimately often aggregate in convergence zones following oceanic currents (Hidalgo-Ruz et al., 2012; Ballent et al., 2013; Ryan, 2015; Kowalski et al., 2016; Chubarnko et al., 2016). Numerical models have been used to predict the dispersion of plastics in coastal seas (Neumann et al., 2014; Isobe et al., 2014, 2015; Mansui et al., 2015; Critchell et al., 2015; Critchell and Lambrechts, 2016; Liubartseva et al., 2016; Welden

\footnotetext{
* Corresponding author.

E-mail address: yfli@yic.ac.cn (Y. Li).
} 

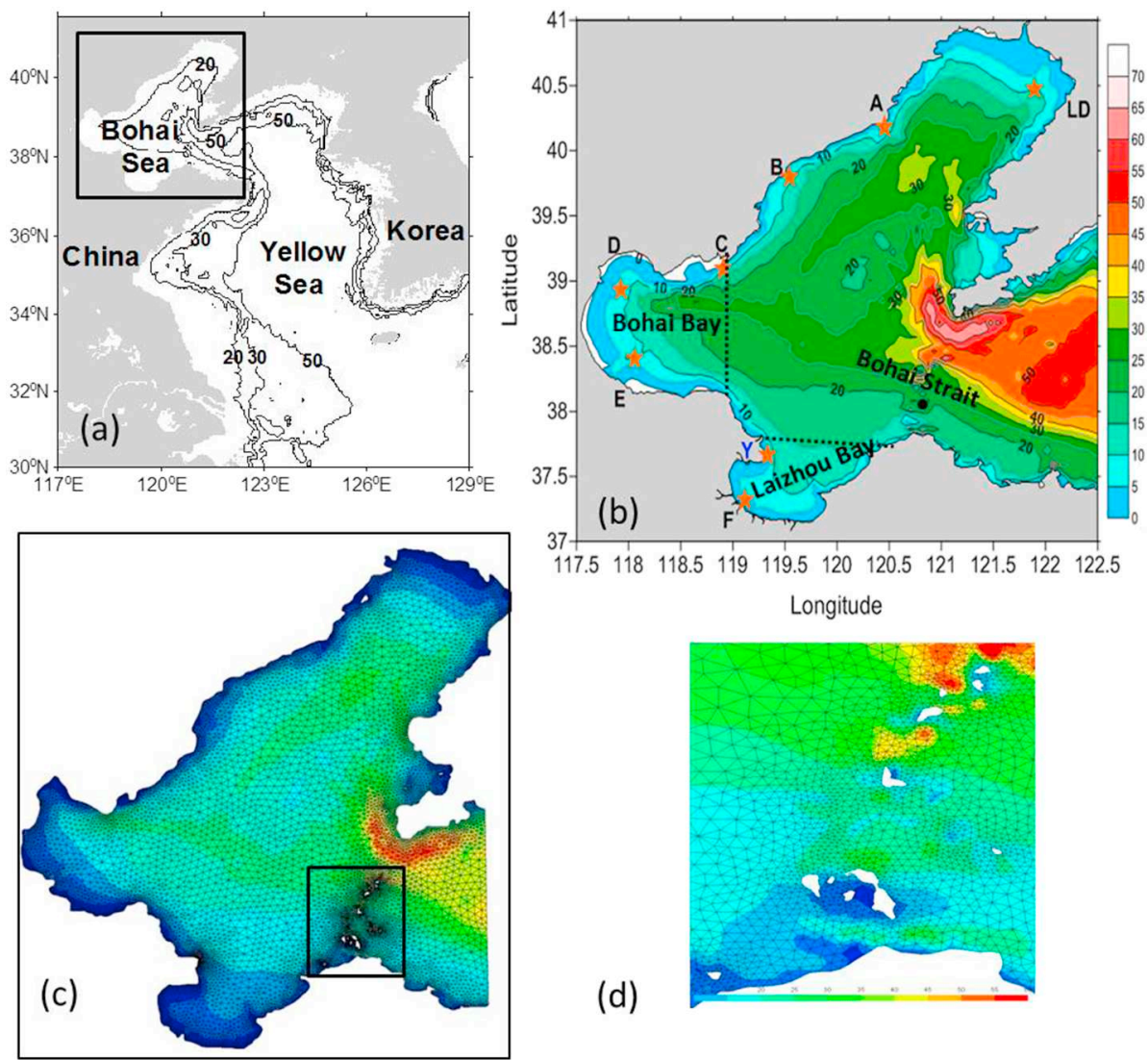

Longitude

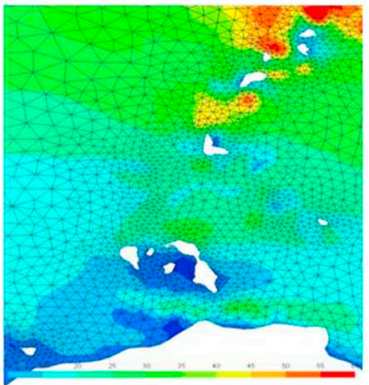

Fig. 1. (a) A general location map of the Bohai Sea. (b) The bathymetry (depth in $\mathrm{m}$ ) and the location of seven coastal macroplastic seeding sites (the stars A to $\mathrm{F}$ and the Yellow River estuary $\mathrm{Y}$ ). The black dot is the location of the YICZR meteorological buoy. (c) The model domain and the numerical mesh. (d) A zoom-in of the mesh in Bohai Strait showing the fine mesh around several islands and shoals. and Lusher, 2017), however field data on plastics at sea are generally lacking to verify these models. We suspect that, because they are poorly flushed, semi-enclosed seas are particularly susceptible to trapping plastics for the long term, such as was predicted from numerical modeling for the Adriatic Sea, the Seto Inland Sea and the Japan Sea, all are semi-enclosed seas (Liubartseva et al., 2016; Isobe et al., 2014, 2015), although field data of plastics at sea were scarce. China is a hotspot of plastic pollution (Jambeck et al., 2015; Fok and Cheung, 2015; J. Li et al., 2015, 2016; Yu et al., 2016; Zhang et al., 2017), particularly on urban beaches and urban sites along the coast of Bohai Sea, a semienclosed sea in Northern China (Fig. 1).

This study was conducted to elucidate the transport processes of plastic particles in the Bohai Sea through numerical experiments after verifying the model against the available field data. The objectives of this study were to: 1 ) to verify against field data a numerical model of the transport of plastics in the Bohai Sea; 2) to quantify the trapping of microplastics; and 3) to evaluate the relative importance of settling rate and source location on the residence time of microplastics in the Bohai Sea and this enables the results to be relevant to other semi-enclosed seas such as the Adriatic Sea, the Seto Inland sea and the Sea of Japan.

\section{Material and methods}

\subsection{Site description}

The Bohai Sea (Fig. 1) is a semi-enclosed shallow water (average depth of $18 \mathrm{~m}$ ) bay located in the northeastern part of China. It is connected to the Yellow Sea on the east through the narrow Bohai Strait ( $\sim 100 \mathrm{~km}$ wide). The Bohai Sea is flushed mainly by episodic storm events and the estimated residence time of water is about 1.6 year (Y.F. Li et al., 2015). The land areas surrounding the Bohai Sea are among the most highly urbanized and industrialized zones in China that discharge large amounts of pollutants into the sea.

\subsection{Microplastics sampling and extraction}

A total of 20 surface water samples (locations shown in Fig. 2b) were collected from August 28 to September 12, 2016, in the Bohai Sea using the Research Vessel Chuangxin-1. Surface water samples were collected using a stainless steel bucket of $5 \mathrm{~L}$ from all the stations while the vessel was stationary. These samples were processed using the method of Su et al. (2016). Each sample was filtered over gridded $5 \mu \mathrm{m}$ cellulose nitrate filter with a $47-\mathrm{mm}$ diameter. All the filters were packed with foil paper and transported to the laboratory for further extraction. The residues on the filters were washed into a glass breaker containing a $30 \%$ of hydrogen peroxide and the beaker was immediately covered with a watch glass to avoid spillage (Nuelle et al., 2014; Zhao et al., 2014). Then the glass beakers were placed on an electric heating plate at $120^{\circ} \mathrm{C}$ for $48 \mathrm{~h}$ in order to remove organic matter mixed in the samples. Then the mixture in the beakers were filtered again over Nylon filters with a $20 \mu \mathrm{m}$ diameter, the filters were then stored for further identification.

The preliminary identification of microplastics in the filtered residues was conducted by visual examination under a Nikon SMZ25 microscope. Three rules were setup to avoid mis-identification of the microplastics following the method of Nor and Obbard (2014) and Peng et al. (2017), namely: first, particles cannot be torn apart with a tweezer; second, particles do not have cellular or organic structures; third, fibers are equally thick throughout their entire length and are not tapered. All the potential microplastics were picked up and sorted based on their shapes and colors. Suspected microplastics were also picked up and sorted separately. Further polymer identification was carried out 

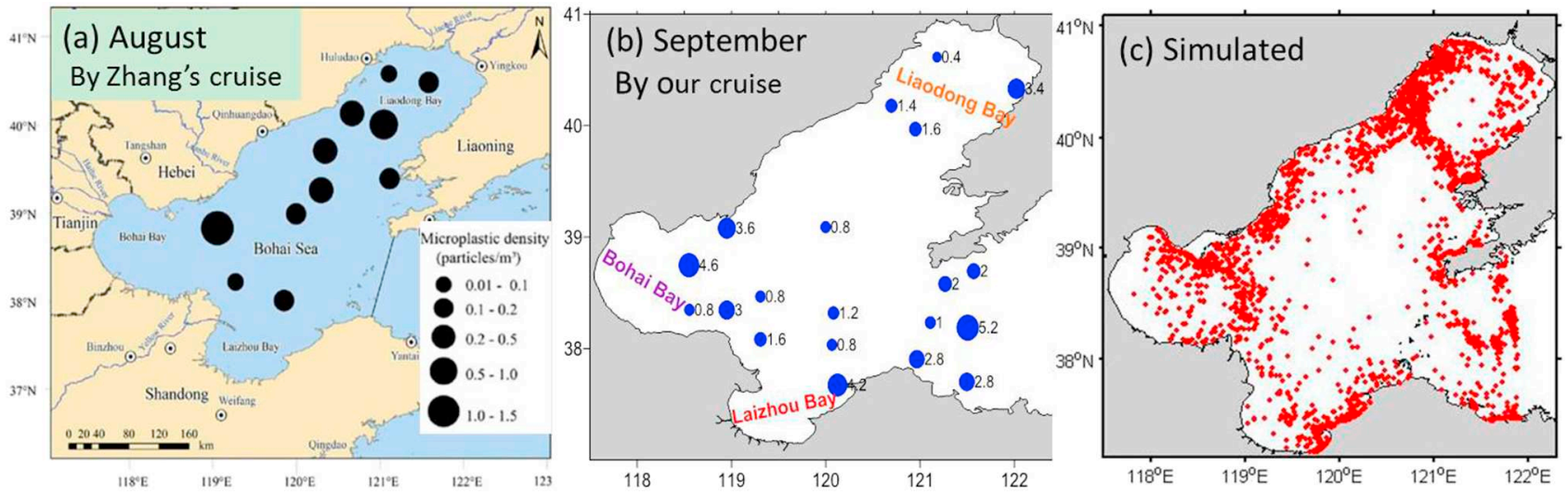

Fig. 2. The observed distribution of microplastics abundance on the surface of the Bohai Sea in (a) August 2016, with abundance in ind/ $\mathrm{m}^{3}$, (b) our observation in September 2016 with abundance in ind $\mathrm{L}^{-1}$; (c) The SLIM model predicted in September 2016 where the red dots indicate the predicted locations of the microplastic particles. (a) is adapted from Zhang et al. (2017). (For interpretation of the references to color in this figure legend, the reader is referred to the web version of this article.)

using the micro-Fourier transform infrared spectroscope for all the suspected microplastics (Tsang et al., 2017; Peng et al., 2017).

\subsection{Plastic oceanography model}

\subsubsection{Hydrodynamic module}

The 2-D vertical integrated model plastic oceanography SLIM model of Critchell et al. (2015) and Critchell and Lambrechts (2016) was used. The hydrodynamic sub-model is a free-surface, hydrostatic, depthaveraged, non-structured mesh, hydrodynamic model, which solves the shallow water equations by a discontinuous Galerkin finite element method (Lambrechts et al., 2008; Wolanski et al., 2013; Gourge et al., 2013; Critchell et al., 2015; Delandmeter et al., 2017; Pham Van et al., 2016; Li et al., 2017).

The mesh is particularly refined in the Bohai Strait where there are several islands (Fig. 1b); it contained 20,020 elements and 9997 nodes. The horizontal resolution was uneven with the highest spatial resolution of $150 \mathrm{~m}$ around the coast and islands, which helped to improve the simulation of inshore movement and the complex currents around islands and headlands. The bathymetry was based on a combination of processed nautical charts with resolutions between 1:240,000 and $1: 100,000$. The model had one open boundary, namely at the Yellow Sea where the $\mathrm{M}_{2}, \mathrm{~S}_{2}, \mathrm{~K}_{1}$ and $\mathrm{O}_{1}$ tides were prescribed, together with the mean sea level and the mean currents that varied along the length of the open boundary. The mean sea level data and the mean current data were provided by CMEMS (Copernicus Marine and Environment Monitoring Service), which provides weekly geostrophic currents based on satellites. The model was also forced by the wind, the wind data were provided by the YICZR meteorological buoy moored in Bohai Strait (Fig. 1). The Yellow River runoff input into the Bohai Sea was also included; the monthly runoff was obtained from Lijin station, located about $86 \mathrm{~km}$ from the river mouth. The simulations started on October 1, 2014 and lasted until September 30, 2016.

\subsubsection{Plastic module}

The plastic transport sub-model uses the advection-diffusion equation to simulate the trajectory of macro- and micro-plastics. The detailed description of the model follows Critchell et al. (2015) and Critchell and Lambrechts (2016). Considering hot spots of microplastic pollutions in the Bohai Sea and river input (Sun et al., 2016; Yu et al., 2016), macroplastics particles were released at seven seeding sites (shown as stars in Fig. 1b). They floated at the surface and were thus transported by the water currents and the wind. The position of each particle was updated at each time step by a forward Euler Lagrangian scheme:
$X^{t+\Delta t}=X^{t}+\left[u^{t}+\alpha W^{t}\right] \Delta t+\sqrt{\frac{2 \Delta t \kappa}{3} r^{t}}$

where $X$ is the particle position ( $\mathrm{x}, \mathrm{y}$ ), $\mathrm{t}$ is the time, $\Delta t$ is the time step, $u$ is the water velocity, $W$ is the wind velocity, $\alpha$ is the wind drift coefficient, $\kappa$ is the diffusivity, and $r^{t}$ is a random vector whose two components are uniformly distributed between -1 and 1 . Further at each time step, some macroplastic particles lost their positive buoyancy and sink; they had a probability to settle on the bottom

$P_{\text {macro }}^{\text {set }}=\frac{\Delta t}{\tau_{\text {set }}}$

where $\tau_{\text {set }}$ is the timescale.

Macroplastic particles degraded into microplastic particles by means of a linear, first-order expression (i.e. a formulation similar to that of radioactive decay). The characteristic time for degradation was $\tau_{\text {deg. }}$. The microplastics were spread all over the water column. They were thus not directly affected by the wind but the random walk simulating their dispersion requires a correction related to the bathymetry gradient to prevent negative numerical dispersion (Spagnol et al., 2002):

$X^{n+1}=X^{n}+\left[u^{n}+\kappa \frac{\nabla H}{H}\right] \Delta t+\sqrt{\frac{2 \Delta t \kappa}{3} r^{n}}$

where $H$ is the total water column depth. Some microplastic particles settled at a rate $w_{\text {set }}$ and the probability to reach the bottom during one time increment was:

$P_{\text {micro }}^{\text {set }}=\frac{w_{\text {set }} \Delta t}{H}$

When a plastic particle reached the coast, it was considered as landed. The degradation rate from macro- to micro-plastic was smaller $\left(0.0003\right.$ day $\left.^{-1}\right)$ for particles in the water column than for particles landed on the coast $\left(0.005 \mathrm{day}^{-1}\right)$ because of physical abrasion by moving sediment. At the same time these landed particles were also resuspended by waves at a characteristic time $\tau_{\text {res }} \approx 5$ days (i.e. a resuspension rate from the coast for both macro- and micro-plastic particles of $0.2 \mathrm{day}^{-1}$ ). These resuspended particles were placed at a random point in the triangle adjacent to the mesh segment where they landed. At each time step, after the particle displacement, resuspension, settling and beaching can occur. By contrast, particles settled on the seafloor were assumed to remain there permanently.

To quantify the relative importance of the source locations and hydrodynamics, a number of scenarios were run. The standard run was set for 20,000 macroplastic particles released at each of these seven seeding sites, with a wind drift coefficient of 0.03 (Matsuzaki, 2016), a 
Table 1

Parameters used in the scenarios.

\begin{tabular}{|c|c|c|}
\hline Parameters & Values & References \\
\hline $\begin{array}{l}\text { Resuspension rate } \\
\left(\text { day }^{-1}\right)\end{array}$ & 0.2 & Critchell and Lambrechts (2016) \\
\hline Degradation rate & 0.005 on land & \\
\hline$\left(\right.$ day $\left.^{-1}\right)$ & 0.0003 in water & \\
\hline Wind drift coefficient & 0.03 & (Matsuzaki, 2016) \\
\hline $\begin{array}{l}\text { Source location } \\
\qquad(\mathrm{A}, \mathrm{B}, \ldots, \mathrm{F} \text { and } \mathrm{Y})\end{array}$ & $\begin{array}{l}7 \text { different locations (shown in } \\
\text { Fig. 1b) }\end{array}$ & $\begin{array}{l}\text { The seeding sites were the six largest harbor cities in the region (A through F) as well as the mouth of Yellow River (Y) } \\
\text { (Sun et al., 2016; Yu et al., 2016). }\end{array}$ \\
\hline $\begin{array}{l}\text { Settling rate } \\
\qquad\left(\mathrm{mm} \mathrm{s}^{-1}\right)\end{array}$ & $5,10,20,30,40,50$ & $\begin{array}{l}\text { Different settling rate has been measured in various experiments (Ballent et al., 2013; Kowalski et al., 2016; } \\
\text { Chubarnko et al., 2016; Khatmullina and Isachenko, 2017; Zhang, 2017) }\end{array}$ \\
\hline Wind forcing & Storm/normal & \\
\hline
\end{tabular}
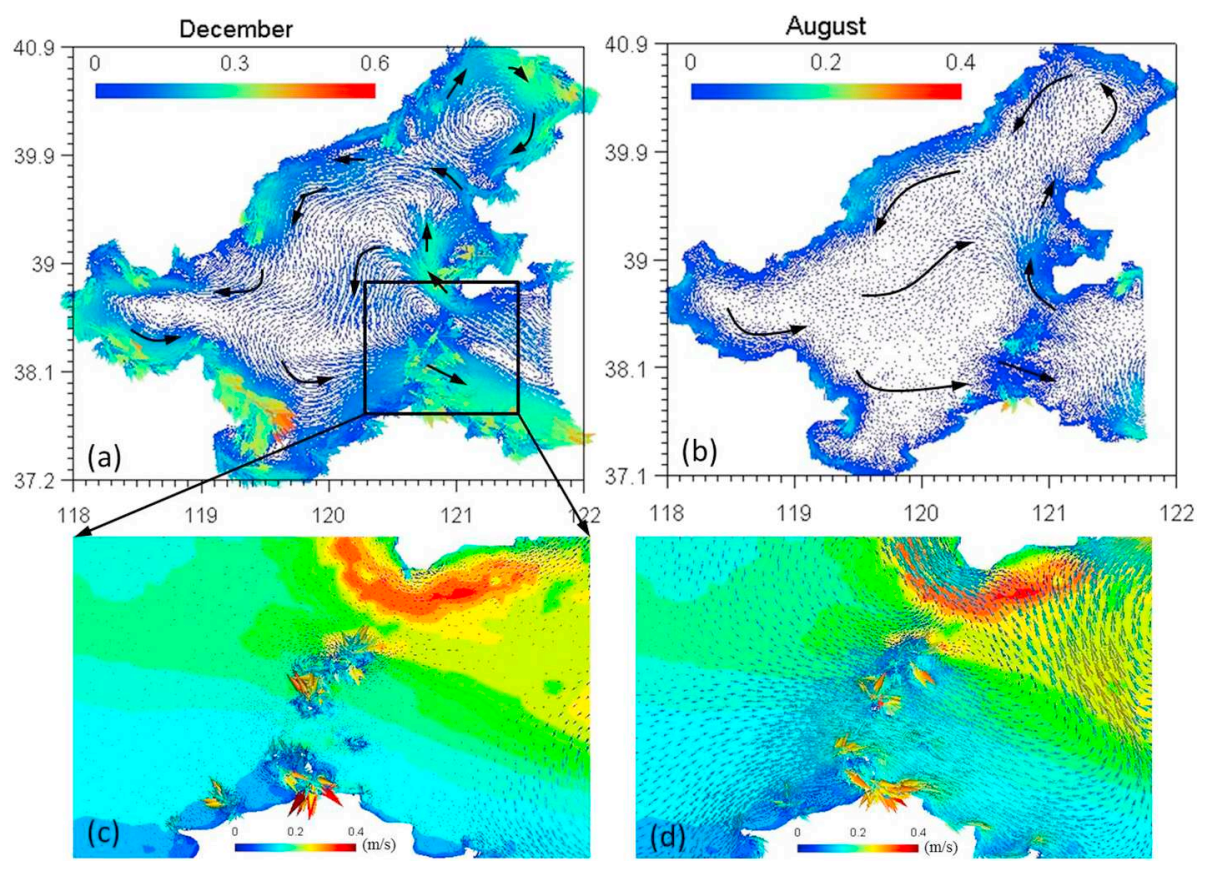

Fig. 3. SLIM model predicted monthly mean circulation (a) in December of 2015 and (b) August of 2016. The corresponding close-ups views of the mean circulation in Bohai Strait during (c) 29-30 October 2015 and (d) 12-13 November 2015. The color bars show the velocity $\left(\mathrm{m} \mathrm{s}^{-1}\right)$. (For interpretation of the references to color in this figure legend, the reader is referred to the web version of this article.) horizontal eddy diffusion coefficient of $20 \mathrm{~m}^{2} \mathrm{~s}^{-1}$, a resuspension rate from the coast for both macro- and micro-plastic particles of 0.2 day $^{-1}$. The time step was $300 \mathrm{~s}$. The settling rate of both macro- and microplastic debris onto the seafloor was set to $5 \mathrm{~mm} \mathrm{~s}^{-1}$. The specific parameters used for scenarios are listed in Table 1 . The 20,000 particles were released once in the beginning, because we wanted to evaluate the evolution of these particles and their final fate (and the time scales) from source (macro-plastics released at urban coastal sites and the Yellow River) to sink (export, trapping, beaching or sinking to the seafloor).

\section{Results}

\subsection{Observed surface distribution}

Fig. 2a shows the micro-plastic distribution measured by Zhang et al. (2017) from August 17 to 22, 2016, using a surface tow with a mesh size of $330 \mu \mathrm{m}$. The average concentration of microplastics in that survey was $0.33 \pm 0.34$ particles $\mathrm{m}^{-3}$. The distribution of microplastic particles on the surface of Bohai Sea in September 2016 from our cruise

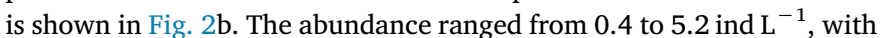
an average of 2.2 ind $\mathrm{L}^{-1}\left(2200 \mathrm{ind}^{-3}\right)$; the average abundance of microplastic particles was much higher than that in the East China Sea with $0.167 \mathrm{ind} / \mathrm{m}^{3}$, but much lower than that in regional rivers and beaches (Zhao et al., 2014; Fok and Cheung, 2015). The size of microplastics ranged from $5 \mu \mathrm{m}$ to $3000 \mu \mathrm{m}$. The types of microplastics found in the surface water was dominated by fibers, and then followed by fragments. Both surveys show a similar spatial distribution of microplastics, namely the abundance of microplastic debris was relatively highest in the three bays (Bohai Bay, Laizhou Bay and Liaodong Bay), and the abundance of microplastic debris was the smallest in the center of the Bohai Sea (Fig. 2b). Our result also show a large abundance in the center of the Bohai Strait, where Zhang et al. (2017) did not have data.

\subsection{Model validation}

The predicted distribution of microplastics in the surface in September 2016 is shown in Fig. 2c. The simulated pattern of distribution compares favorably with our field observations (Fig. 2b), and is also similar to Zhang's data (Fig. 2a). In particular the model predicted correctly that there are accumulation zones of plastic particles in the three bays and in the center of the Bohai Strait just north of the islands, and that the lowest concentration occurred in the center of the Bohai Sea.

\section{Discussion}

This study is the first time that a plastic oceanography model has been successfully confronted with field data of the plastic distribution at sea. The model predicted correctly the spatial patterns of microplastics distribution in the Bohai Sea. The model also predicted that a large fraction of the released plastic particles was retained nearshore, 

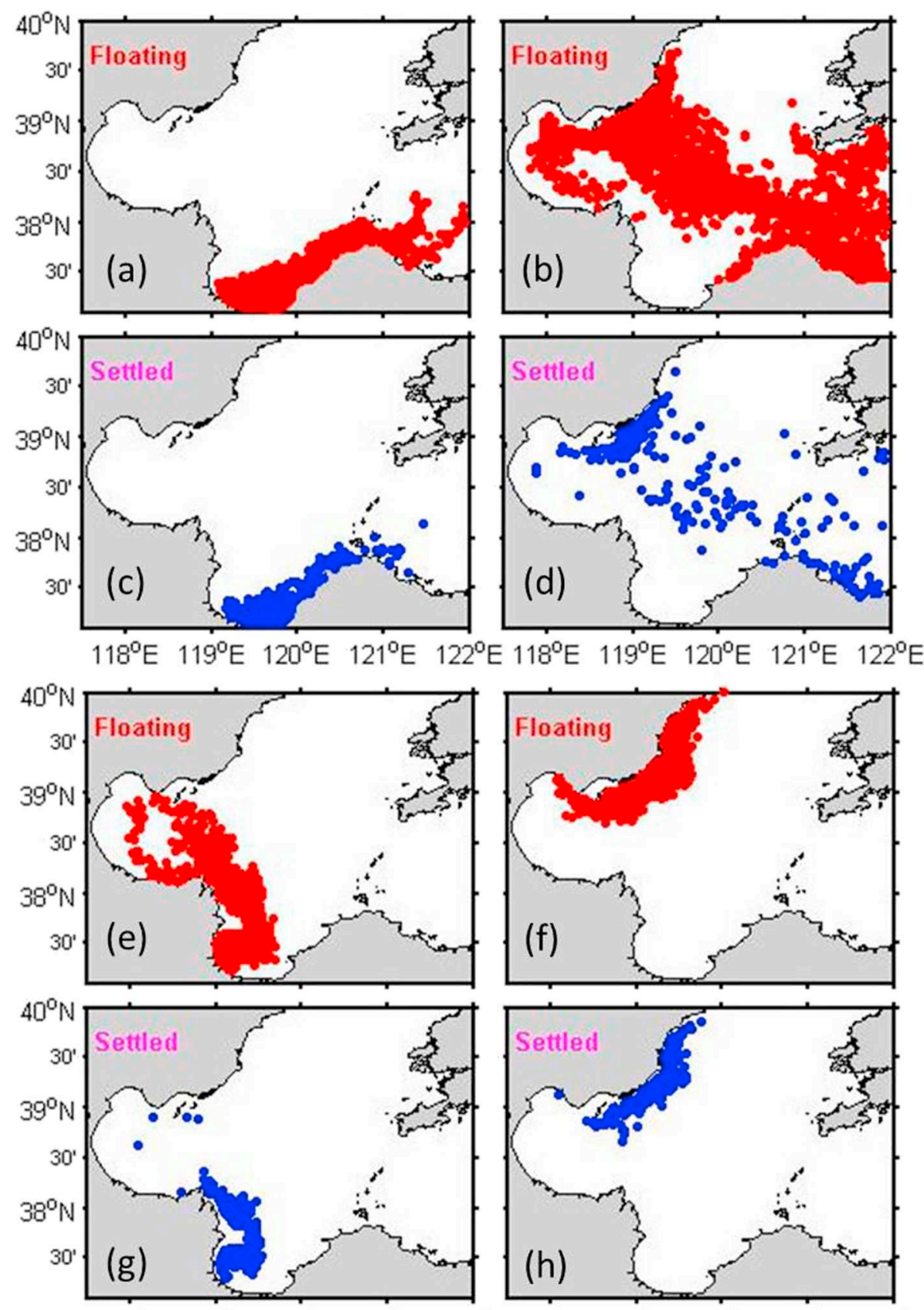

$118^{\circ} \mathrm{E} 119^{\circ} \mathrm{E} 120^{\circ} \mathrm{E} 121^{\circ} \mathrm{E} 122^{\circ} \mathrm{E} 118^{\circ} \mathrm{E} 119^{\circ} \mathrm{E} 120^{\circ} \mathrm{E} \quad 121^{\circ} \mathrm{E} 122^{\circ} \mathrm{E}$

Fig. 4. The predicted seasonal distribution of microplastics in the Bohai Sea for both suspended and settled particles in winter and summer for source $\mathrm{Y}$ and $\mathrm{C}$ (shown in Fig. 1). (a)-(d): in winter; (e)-(h) in summer. (a, c, e, g) were for source Y which was the Yellow River Estuary, and (b, d, f and h) were for source C.

but there are no field data to validate this prediction.

The average concentration was typically a thousand times smaller in August 2016 (Zhang et al., 2017) than that in September 2016 (our data); we suggest that these differences are a result of Zhang's much larger mesh size ( $330 \mu \mathrm{m}$ versus our mesh size of $5 \mu \mathrm{m})$; we suggest that their $330 \mu \mathrm{m}$ meshes underestimated the plastic particle concentration because the majority of microplastics were smaller than $40 \mu \mathrm{m}$ (Nor and Obbard, 2014).

In view of the qualitative success of our model, we used the model to test the sensitivity of various processes, in particular to focus on the role of the seasonal currents and wind, the settling rate and the macroplastic source locations (Table 1).

\subsection{The influence of seasonal winds}

The predicted circulation in the Bohai Sea has a clear seasonal variation between winter and summer circulation patterns shown in Fig. 3a and b, this result is in agreement with other studies (Hainbuchera et al., 2004; Wang et al., 2010; Li et al., 2005). As shown in Fig. 3, in the winter a weak anti-clockwise gyre was formed in the south Bohai Bay, while a strong wind-driven coastal boundary flow formed along the coastline of Laizhou Bay to finally flowing out to the Yellow Sea in the south of Bohai Strait. In summer, the currents are weaker and there was a clockwise eddy in the center of the Bohai Sea while the coastal boundary layer current was much weaker and even vanished in places. 


\section{Boreal wind}
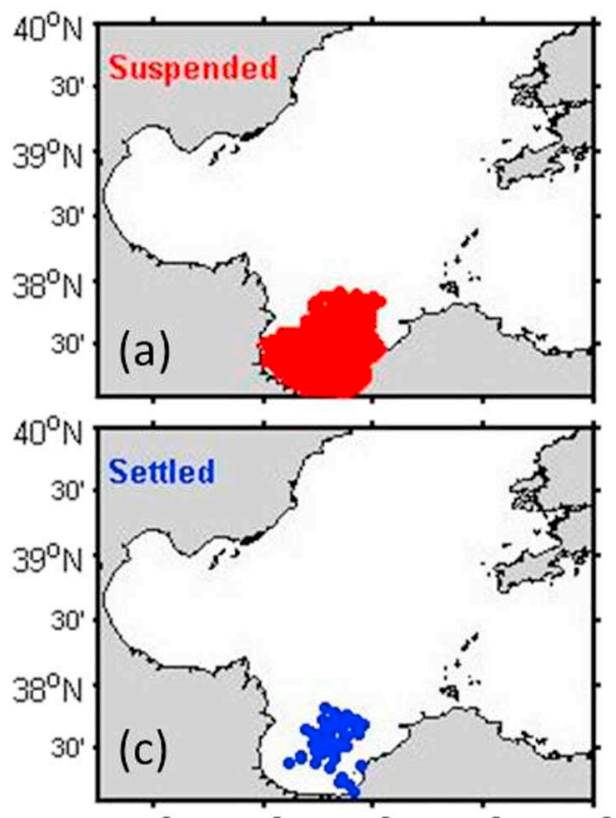

Strong wind
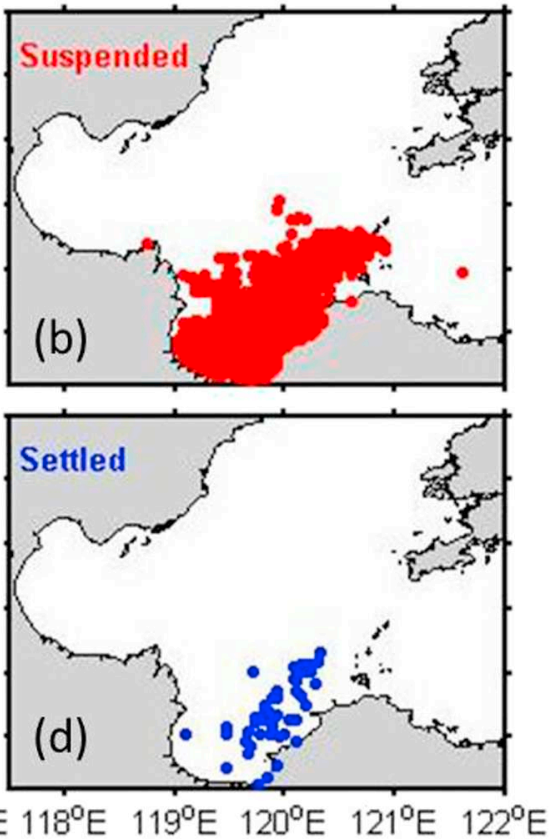

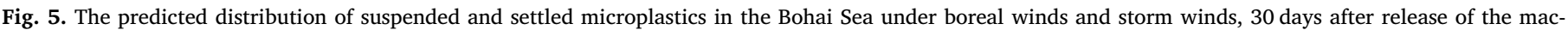
roplastics at site F (see location in Fig. 1) in winter, (a) and (c) under boreal winds, (b) and (d) under strong winds.

This seasonally-averaged circulation however varied quite rapidly, at time scales typically of one month but done week during storms, as the wind waxed and waned and as long waves propagated from/to the Yellow Sea and pushing water in/out of the Bohai Sea (Fig. 3c and d; Y.F. Li et al., 2015). It is apparent that the islands and shoals in the Bohai Strait have a large influence on the through-Strait flows. The residence time of water in the Bohai Sea is $>1$ year (Y.F. Li et al., 2015), which is less than the residence time of microplastics particles as these can be sequestered in the sediment; this monthly and seasonal variability of the mean circulation can be seen as a meso-scale mixing process for microplastics.

In winter, microplastics originating from macroplastics released at the Yellow River mouth (seeding site Y) moved southerly along the east coast of Laizhou Bay and flowed out from the south of the Bohai Strait (Fig. 4a and c); microplastics originating from macroplastics released at the seeding site $C$ spread southeasterly and finally out of Bohai Strait (Fig. 4b and d). In contrast, in summer, microplastic particles both from the Yellow River Mouth (seeding site $\mathrm{Y}$ ) and from seeding site C spread offshore very little (Fig. 4e and $\mathrm{f}$ ) as a result of the weaker coastal circulation in summer, and basically remained trapped locally (Fig. $4 \mathrm{f}$ and $\mathrm{h}$ ).

Overall, the modeling results clearly demonstrated that the seasonal distribution of microplastics was driven by the seasonally varying oceanographic conditions and that plastic trapping was nearly $100 \%$ during calm weather conditions. This finding agrees with similar findings of high local trapping in the Adriatic Sea (Liubartseva et al., 2016).

\subsection{The influence of storm events}

The effect of winds was examined through two sets of numerical experiments using both boreal winds and winter storm winds ( 3 times stronger than the boreal wind). Here the boreal wind is taken as the northerly wind observed at the YICZR buoy during the winter of 2015. We also chose the seeding site $\mathrm{F}$ as the seeding source. The simulated distributions of microplastics in suspension in Laizhou Bay 80 days after initial release are illustrated in Fig. 5. The modeling results revealed that the storm winds in winter drove plastic particles much farther from the source than boreal winds did, and even exported them to the Yellow Sea. The same effect was also predicted for settled microplastics at the bottom (Fig. 5).

\subsection{Dependence of the residence time on the settling rate}

The settling velocity of microplastics is poorly known; to examine its relative influence it was set in the numerical experiments at $5,10,20$, 30,40 and $50 \mathrm{~mm} \mathrm{~s}^{-1}$, which is a range of value reflecting the few observations (e.g. Hidalgo-Ruz et al., 2012; Ballent et al., 2013; Kowalski et al., 2016; Chubarnko et al., 2016).

For typical currents in the Bohai Sea, a sinking particle may transit horizontally from its point of origin a distance of $\sim 1 \mathrm{~km}$ for a fast settling rate to $\sim 35 \mathrm{~km}$ for a slow settling rate. Thus the settling rate is expected to strongly influence the fate of plastics. Indeed, the model reveals that; Fig. 6 shows the time series of the number of macroplastics and microplastics in Bohai Bay and Laizhou Bay for different values of the settling velocity. The number of macroplastic and microplastic particles in the water column decreased gradually with increased settling rate. The number of microplastics particles showed similar variations in Bohai and Laizhou Bays (Fig. 6b and d); both bays showed a rapid decrease after 50 days following strong NW wind at that time. For macroplastics the pattern of variation in Bohai Bay (Fig. 6a) and Laizhou Bay (Fig. 6c) was different; further the pattern showed temporal fluctuations that can be due to the varying wind, the Yellow River varying discharge, and a long wave in the Yellow Sea impacting on the Bohai Sea (Fig. 7a). In Laizhou Bay, macroplastics moved out of the bay and returned back and forth in the first 20 days, until a rapid decrease later on due to a wind change from SW to NW and a further wind shift at 30 days.

All external parameters (wind, river discharge, Mean Sea Level) are important, hence there is no steady state in the distribution of plastics in the Bohai Sea. It is patchy and unsteady, therefore hard to sample reliably. 

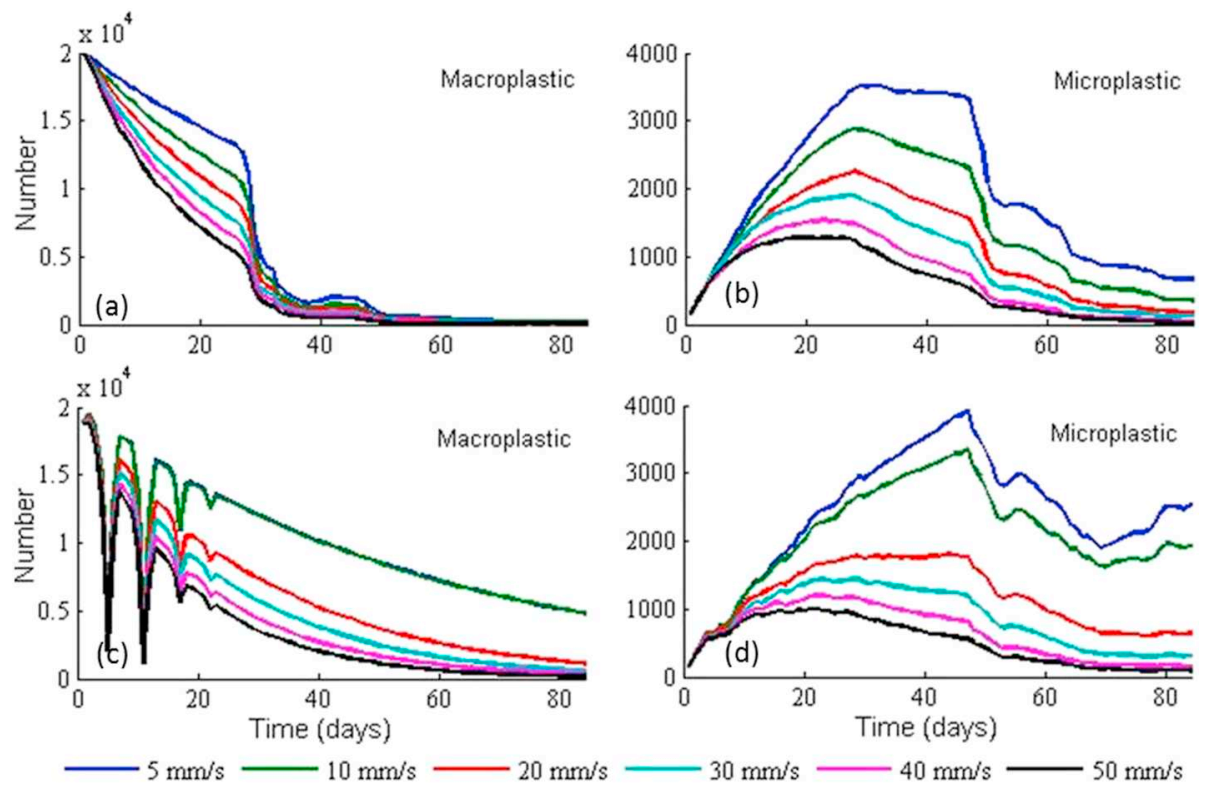

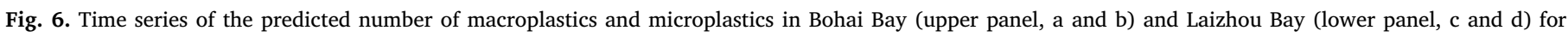
different values of sinking rates during winter. Days started from the beginning of simulation.
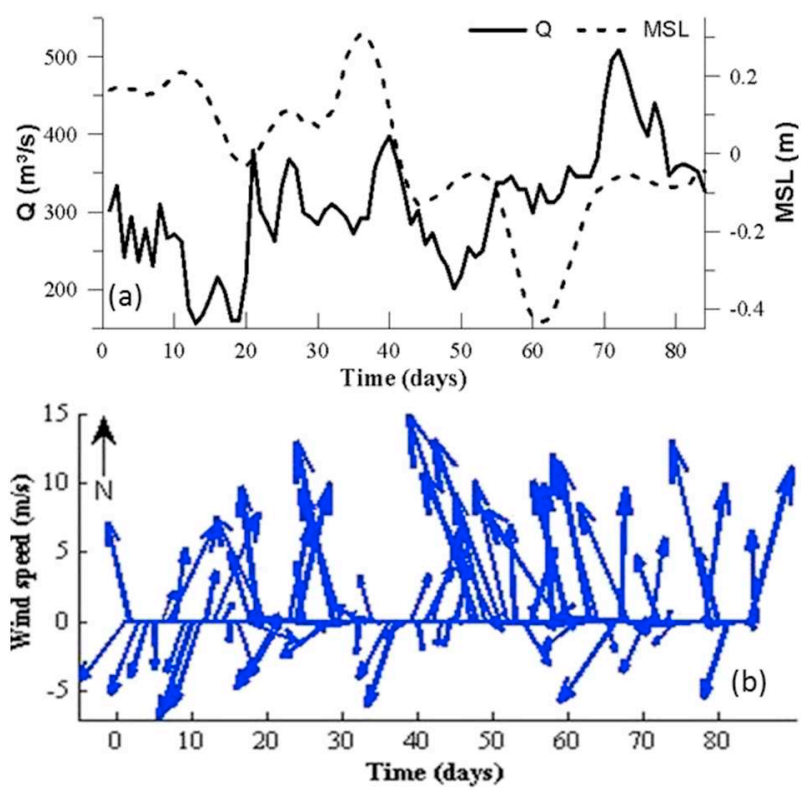

Fig. 7. Time-series plot of (a) the Yellow River discharge (Q), the mean sea level (MSL) in the Bohai Strait and (b) the wind in the Bohai Strait (b). Days started from the beginning of simulation.

\subsection{The importance of source locations}

Our simulation showed that in winter after released 80 days, about half of particles released from central coastal zone (seeding sites B and C) were transported out of the Bohai Sea, which is explained by their locations within the main currents (Fig. 3). In contrast, $<10 \%$ of plastics from seeding sites $\mathrm{D}$ and $\mathrm{E}$, which are the most heavily populated coasts in Bohai Bay, was flushed out of the Bohai Sea in winter. There was even less flushing (i.e. there was more trapping) in summer. Thus microplastics from the most heavily populated coasts are virtually all trapped and thus they most threaten the nearshore marine ecosystem.

\section{Conclusion}

Field data and the modeling suggest that there is a direct relationship between local sources of plastics and the distribution of microplastics in the Bohai Sea, China. Most plastics are trapped in the Bohai Sea, which is a semi-enclosed sea. However a detailed knowledge of the sources of plastics is required to make a more robust estimate of the fate of plastics in the Bohai Sea and the threat that they pose to the ecosystem. Thus the Bohai Sea appears to be a major sink of plastic debris released from industrial and domestic uses. We demonstrate that is due to the slow oceanography flushing and thus we suggest that similar high trapping of plastics occur in other semi-enclosed seas worldwide, such as the Adriatic Sea (Liubartseva et al., 2016), the Seto Inland Sea (Isobe et al., 2014), and the Sea of Japan (Isobe et al., 2015).

The model could readily be modified to include positively buoyant microplastics, which could then accumulate near the surface in a boundary layer typically 1-2 $\mathrm{m}$ thick (Kooi et al., 2016), although present estimates are that the proportion of such particles may be small probably due to biofouling and incorporation in sediment flocs in suspension that make the microplastic particles sink (Reisser et al., 2013; Ryan, 2015; Imhof and Laforsch, 2016; Kaiser et al., 2017; Möhlenkamp et al., 2018). Similarly, a 3D plastic oceanography model could be another development in the future; however the Bohai Sea is stratified only in summer and then only in the northern region of the Bohai Strait (Y.F. Li et al., 2015). The three bays where most plastics are found and the central region of the Bohai Sea are shallow and vertically wellmixed; hence the 2D model is justified though a 3D model clearly could better resolve plastic oceanography in the deep waters of the northern region of the Bohai Strait. The need to include such additional processes in the model should be based on field evidence.

Our modeling results indicate that the nearshore benthic sediment is now a major reservoir of microplastics, however field data are lacking on that aspect. This likely causes ecological risks to benthic organisms, similar to what has been observed in bivalves and mussels in the East China Sea (J. Li et al., 2015, 2016). Considering the large-scale aquaculture industry in this region, such environmental risks to both human health and ecosystems should become a priority research item in further field surveys to produce data to improve numerical models.

The predicted plastic debris varying in days in the Bohai Sea suggests that the distribution of microplastic in water is unsteady and 
patchy and thus difficult to sample, to model and to verify models. Another major implication of our study is that although the majority of the released microplastics were retained inside the Bohai Sea, a fraction of the particles might be carried out to the Yellow Sea during winter storms, and thus impacts that ecosystem also.

\section{Acknowledgement}

This research was financially supported by the National Key Research and Development Plan of China (2016YFC1402202), the Chinese Academy of Sciences (KYSB20160003 and QYZDJ-SSWDQC015), the National Natural Science Foundation of China (41806029), and the Natural Science Foundation of Shandong Province of China (ZR2018QD006), and TropWATER at James Cook University.

\section{References}

Auta, H.S., Emenike, C.U., Fauziah, S.H., 2017. Distribution and importance of microplastics in the marine environment: a review of the sources, fate, effects, and potential solutions. Environ. Int. 102, 165-176.

Ballent, A., Pando, S., Purser, A., Juliano, M.F., Thomsen, L., 2013. Modelled transport of benthic marine microplastic pollution in the Nazaré Canyon. Biogeosciences 10, 7957-7970.

Breivik, O., Allen, A.A., Maisondieu, C., Roth, J.C., 2011. Wind-induced drift of objects at sea: the leeway field method. Appl. Ocean Res. 33, 100-109.

Browne, M.A., Crump, P., Niven, S.J., Teuten, E.L., Tonkin, A., Galloway, T., Thompson, R.C., 2011. Accumulations of microplastic on shorelines worldwide: sources and sinks. Environ. Sci. Technol. 45, 9175-9179.

Chubarnko, I., Bagaev, A., Zobkov, M., Esiukova, E., 2016. On some physical and dynamical properties of microplastic particles in marine environment. Mar. Pollut. Bull. 108, 105-112.

Claessens, M., Meester, S.D., Landuyt, L.V., Clerck, K.D., Janssen, C.R., 2011. Occurrence and distribution of microplastics in marine sediments along the Belgian coast. Mar. Pollut. Bull. 62, 2199-2204.

Cole, M., Lindeque, P., Halsband, C., Galloway, T.S., 2011. Microplastics as contaminants in the marine environment: a review. Mar. Pollut. Bull. 62, 2588-2597.

Cozar, A., Echevarria, F., Gonzalez-Gordillo, J.I., Irigoien, X., Ubeda, B., Hernandez-Leon, S., Palmae, A.T., Navarrof, S., Garcia-de-Lomasa, J., Ruizg, A., Fernandez-de-Puelles, M.L., Duartei, C.M., 2014. Plastic debris in the open ocean. P. Natl. Acad. Sci. U.S.A. 111 (28), 10239-10244.

Critchell, K., Lambrechts, J., 2016. Modeling accumulation of marine plastics in the coastal zone: what are the dominant physical processes? Estuar. Coast. Shelf Sci. 171, 111-122.

Critchell, K., Grech, A., Schlaefer, J., Andutta, F.P., Lambrechts, J., Wolanski, E., Hamann, M., 2015. Modelling the fate of marine debris along a complex shoreline: lessons from the Great Barrier Reef. Estuar. Coast. Shelf Sci. 167, 414-426.

Delandmeter, P., Lambrechts, J., Marmorino, G.O., Legat, V., Wolanski, E., Remacle, J.-F., Chen, W., Deleersnijder, E., 2017. Submesoscale tidal eddies in the wake of coral islands and reefs: satellite data and numerical modelling. Ocean Dyn. 67, 897-913.

Desforges, J.-P.W., Galbraith, M., Dangerfield, N., Ross, P.S., 2014. Widespread distribution of microplastics in subsurface seawater in the NE Pacific Ocean. Mar. Pollut. Bull. 79, 94-99.

Eriksen, M., Lebreton, L.C.M., Carson, H.S., Thiel, M., Moore, C.J., Borerro, J.C., Galgani, F., Ryan, P.G., Reisser, J., 2014. Plastic pollution in the world's oceans: more than 5 trillion plastic pieces weighing over 250,000 tons afloat at sea. PLoS One 9 (12), e111913.

Fazey, F.M.C., Ryan, P.G., 2016. Biofouling on buoyant marine plastics: an experimental study into the effect of size on surface longevity. Environ. Pollut. 210, 354-360.

Fok, L., Cheung, P.K., 2015. Hong Kong at the Pear River estuary: a hotpot of microplastic pollution. Mar. Pollut. Bull. 99, 112-118.

Gourge, O., Baeyens, W., Chen, M.S., de Brauwere, A., de Brye, B., Deleersnijder, E., Elskens, M., Legat, V., 2013. A depth-averaged two-dimensional sediment transport model for environmental studies in the Scheldt Estuary and tidal river network. J. Mar. Syst. 128, 27-39.

Hainbuchera, D., Wei, H., Thomas, P., Sundermanna, J., Feng, S., 2004. Variability of the Bohai Sea circulation based on model calculations. J. Mar. Syst. 44, 153-174.

Hidalgo-Ruz, V., Gutow, L., Thompson, R.C., Thiel, M., 2012. Microplastics in the marine environment: a review of the methods used for identification and quantification. Environ. Sci. Technol. 46, 3060-3075.

Hogan, P.J., Hurlburt, H.E., 2005. Sensitivity of simulated circulation dynamics to the choice of surface wind forcing in the Japan/East Sea. Deep-Sea Res. II 52, 1464-1489.

Imhof, H.K., Laforsch, C., 2016. Hazardous or not - are adult and juvenile individuals of Potamopyrgus antipodarum affected by non-buoyant microplastic particles? Environ. Pollut. 218, 383-391.

Isobe, A., Kubo, K., Tamura, Y., Kako, S., Nakashima, E., Fujii, N., 2014. Selective transport of microplastics and mesoplastics by drifting in coastal waters. Mar. Pollut. Bull. 89, 324-330.

Isobe, A., Tokai, T., Uchida, K., Iwasaki, S., 2015. East Asian seas: a hot spot of pelagic microplastics. Mar. Pollut. Bull. 101, 618-623.

Jambeck, J.R., Geyer, R., Wilcox, C., Siegler, T.R., Perryman, M., Andrady, A., Narayan, R., Law, K.L., 2015. Plastic waste inputs from land into the ocean. Science 347 (6223), 768-771.

Kaiser, D., Kowalski, N., Waniek, J.J., 2017. Effects of biofouling on the sinking behavior of microplastics. Environ. Res. Lett. 12, 124003.

Khatmullina, L., Isachenko, I., 2017. Setting velocity of microplastic particles of regular shapes. Mar. Pollut. Bull. 114, 871-880.

Kooi, M., Reisser, J., Slat, B., Ferrari, F.F., Schmid, M.S., Cunsolo, S., Brambini, R., Noble, K., 2016. The effect of particle properties on the depth profile of buoyant plastics in the ocean. Sci. Rep. 6, 33882. https://doi.org/10.1038/srep33882.

Kowalski, N., Reichardt, A.M., Waniek, J.J., 2016. Sinking rates of microplastics and potential implications of their alteration by physical, biological, and chemical factors. Mar. Pollut. Bull. 109, 310-319.

Lambrechts, J., Hanert, E., Deleersnijder, E., Bernard, P.-E., Legat, V., Remacle, J.-F., Wolanski, E., 2008. A multi-scale model of the hydrodynamics of the whole Great Barrier Reef. Estuar. Coast. Shelf Sci. 79, 143-151.

Lebreton, L.C.M., Borrero, J.C., 2013. Modeling the transport and accumulation floating debris generated by the 11 March 2011 Tohoku tsunami. Mar. Pollut. Bull. 66, 53-58.

Li, G.S., Wang, H.L., Li, B.L., 2005. A model study on seasonal spatialtemporal variability of the Lagrangian residual circulations in the Bohai Sea. J. Geogr. Sci. 15, 273-285.

Li, Y.F., Wolanski, E., Zhang, H., 2015. What processes control the net currents through shallow straits? A review with application to Bohai Strait, China. Estuar. Coast. Shelf Sci. 158, 1-11.

Li, J., Yang, D., Li, L., Jabeen, K., Shi, H., 2015. Microplastics in commercial bivalves from China. Environ. Pollut. 207, 190-195.

Li, J., Qu, X., Su, L., Zhang, W., Yang, D., Kolandhasamy, P., Li, D., Shi, H., 2016. Microplastics in mussels along the coastal waters of China. Environ. Pollut. 214, $177-184$.

Li, Y.F., Martins, F., Wolanski, E., 2017. Sensitivity analysis of the physical dynamics of the Fly River plume in Torres Strait. Estuar. Coast. Shelf Sci. 194, 84-91.

Liubartseva, S., Coppini, G., Lecci, R., Creti, S., 2016. Regional approach to modeling the transport of floating plastic debris in the Adriatic Sea. Mar. Pollut. Bull. 103, $115-127$.

Lobelle, D., Cunliffe, M., 2011. Early microbial formation on marine plastic debris. Mar. Pollut. Bull. 62, 197-200.

Lusher, A., Tirelli, Valentina, O'Connor, I., Officer, R., 2015. Microplastics in Arctic polar waters: the first reported values of particles in surface and sub-surface samples. Sci. Rep. 5, 14947.

Mansui, J., Molcard, A., Ourmieres, Y., 2015. Modelling the transport and accumulation of floating marine debris in the Mediterranean basin. Mar. Pollut. Bull. 91, 249-257.

Matsuzaki, Y., 2016. In situ estimates of horizontal turbulent diffusivity at the sea surface for oil transport simulation. Mar. Pollut. Bull. 117, 34-40.

Möhlenkamp, P., Purser, A., Thomsen, L., 2018. Plastic microbeads from cosmetic products: an experimental study of their hydrodynamic behaviour, vertical transport and resuspension in phytoplankton and sediment aggregates. Elem. Sci. Anth 6, 61. https://doi.org/10.1525/elementa.317.

Neumann, D., Callies, U., Matthies, M., 2014. Marine litter ensemble transport simulations in the southern North Sea. Mar. Pollut. Bull. 86, 219-228.

Nor, M.N.H., Obbard, J.P., 2014. Microplastics in Singapore's coastal mangrove ecosystems. Mar. Pollut. Bull. 79, 278-283.

Nuelle, M.T., Dekiff, J.H., Remy, D., Fries, E., 2014. A new analytical approach for monitoring microplastics in marine sediments. Environ. Pollut. 184, 161-169.

Peng, G., Zhu, B., Yang, D., Su, L., Shi, H., Li, D., 2017. Microplastics in sediments of the Changiiang Estuary, China. Environ. Pollut. 225, 283-290.

Pham Van, C., Brye de, B., Deleersnijder, E., Hoitink, A.J.F., Sassi, M., Spinewine, B., Hidayat, H., Soares-Frazao, S., 2016. Simulations of the flow in the Mahakam riverlake-delta system, Indonesia. Environ. Fluid Mech. 16, 603-633.

Reisser, J., Shaw, J., Wilcox, C., Hardesty, B.D., Proietti, M., Thums, M., Pattiaratchi, C., 2013. Marine plastic pollution in waters around Australia: characteristics, concentrations, and pathways. PLoS One 8 (11), e80466. https://doi.org/10.1371/ journal.pone.0080466.

Ryan, P.G., 2015. Does size and buoyancy affect the long-distance transport of floating debris. Environ. Res. Lett. 10, 084019.

Spagnol, S., Wolanski, E., Deleersnijder, E., Brinkman, R., McAllister, F., Cushman-Roisin, B., Hanert, E., 2002. An error frequently made in the evaluation of advective transport in two-dimensional Lagrangian models of advection-diffusion in coral reef waters. Mar. Ecol.-Prog. Ser. 235, 299-302.

Su, L., Xue, Y., Li, L., Yang, D., Kolandhasamy, P., Li, D., Shi, H., 2016. Microplastics in Taihu Lake, China. Environ. Pollut. 216, 711-719.

Sun, C., Jiang, F., Li, J., Zheng, L., 2016. The research progress in source, distribution, ecological and environmental effects of marine microplastics. Adv. Mar. Sci. 34, 449-461 (Chinese abstract).

Tsang, Y.Y., Mak, C.W., Liebich, C., Lam, S.W., Sze, E.T.-P., Chan, K.M., 2017. Microplastic pollution in the marine waters and sediments of Hong Kong. Mar. Pollut. Bull. 115, 20-28.

Van Cauwenberghe, L., Vanreusel, A., Mees, J., Janssen, C.R., 2013. Microplastic pollution in deep-sea sediments. Environ. Pollut. 182, 495-499. 
Wang, J., Shen, Y., Guo, Y., 2010. Seasonal circulation and influence factors of the Bohai Sea: a numerical study based on Lagrangian particle tracking method. Ocean Dyn. 60, $1581-1596$.

Welden, N.A.C., Lusher, A.L., 2017. Impacts of changing ocean circulation on the distribution of marine microplastic litter. Integr. Environ. Assess. Manag. 13, 483-487.

Wolanski, E., Lambrechts, J., Thomas, C., Deleersnijder, E., 2013. The net water circulation through Torres Strait. Cont. Shelf Res. 64, 66e74.

Yu, X., Peng, J., Wang, J., Wang, K., Bao, S., 2016. Occurrence of microplastics in the beach sand of the Chinese inner sea: the Bohai Sea. Environ. Pollut. 214, 722-730.
Zhang, H., 2017. Transport of microplastics in coastal seas. Estuar. Coast. Shelf Sci. 199, 74-86.

Zhang, W., Zhang, S., Wang, J., Wang, Y., Wu, J., Wang, P., Lin, X., Ma, D., 2017.

Microplastic pollution in the surface waters of the Bohai Sea, China. Environ. Pollut. 231, 541-548.

Zhao, S., Zhu, L., Wang, T., Li, D., 2014. Suspended microplastics in the surface water of the Yangtze Estuary system, China: first observations on occurrence, distribution. Mar. Pollut. Bull. 86, 562-568. 